Bayero Journal of Pure and Applied Sciences, 11(1): 451 - 454

ISSN 2006 - 6996

\title{
PREVALENCE OF TICKS ON DOGS IN JOS, PLATEAU STATE, NIGERIA
}

\author{
Shitta, K.B. ${ }^{1 *}$; James-Rugu N.N. ${ }^{2}$ and Badaki, J.A. ${ }^{1}$ \\ ${ }^{1}$ Department of Biological Sciences, Federal University Lokoja, P.M.B. 1154, Lokoja, Kogi State, \\ Nigeria. \\ ${ }^{2}$ Department of Zoology, University of Jos, P.M.B. 2084, Jos Plateau State, Nigeria \\ *Corresponding Author email: kefasshitta@yahoo.com
}

kefas.shitta@fulokoja.edu.ng

\begin{abstract}
Ticks and tick-borne diseases have in addition to other socio-economic parameters, constituted major setbacks to the development of an economically viable livestock industry in Nigeria and other parts of the world. The prevalence of ticks on dogs brought to ECWA Veterinary clinic and Jos Veterinary clinic all in Jos Plateau State was studied. A total of 1,146 ticks were collected from 300 dogs randomly selected. Three species of ticks all from the family ixodidae were encountered and identified in order of abundance namely; Rhipicephalus sanguineus, Boophilus decoloratus and Haemaphysalis leachii. Of the 154 male dogs examined $70(45.16 \%)$ were infested with ticks. Of the remaining 146 female counterpart 85(54.84\%) were infested. The investigation further revealed that adolescent dogs were more susceptible to tick infestation $73(47.10 \%)$ than the adult hosts $48(30.90 \%)$ when compared to the young dogs or puppies who were the least infested $34(22.00 \%)$. Statistical analysis using Chi-Square, showed a significant difference in the infestation rate between sexes of dogs and among tick species $(p<0.05)$ however, such difference was not observed in the ages of dogs and tick species ( $p>0.05)$. Based on these findings, any strategy intended at mitigating the problems of tick infestation of dogs in Jos Plateau and the country at large should take into account the identified tick species.

Keywords: Prevalence, ticks, dogs, Jos, Plateau State, Nigeria.
\end{abstract}

\section{INTRODUCTION}

Dogs are trained and used to unravel criminal intelligence by law enforcement agents, others keep them as pets and to others they serve as meet. In some communities they are used for hunting and sports (Arong et al, 2011 and Hoogstraal, 1956). Ticks are vectors of important haemoparasitic diseases of dogs leading to weakness, depression, irritation and splenomegaly, surpassing all other arthropods, apart from mosquitoes, as disease agents (Hoogstraal, et al, 1964). These haemoparasitic disease such as Haemobatonella sp and Babesia canis constitute some identified diseases that poses a lot of challenge to the health and productivity status of these important animal (James-Rugu 2001, Zeleke and Beleke 2004). In Africa, as in other tropical and sub-tropical regions of the world, ticks and tick-borne disease in addition to other socio-economic parameters have constituted major impediments to the development of the livestock industry (Mohammed and Agbede, 1980; De-Castro, 1997; Pegram, 1976 and George, 2003). In Jos Plateau, ticks and tickborne disease cause considerable losses to the livestock economy (James-Rugu, 2002 and Hoogstraal, 1958). Preliminary information about the species of ticks infesting dogs is crucial for the planning and implementation of an effective tick control strategy.

Studies have been conducted on ticks and tickborne diseases of cattle and small ruminants on the Jos Plateau however, work on ticks of dogs on the plateau is scanty despite the vital role dogs play in the livelihood of the people in the Jos Plateau and the likely impact of ticks on their productivity. This work was therefore, initiated to improve on already existing baseline information on ticks and to evaluate the prevalence of ticks on dogs in this geographical zone.

\section{MATERIALS AND METHODS}

\section{Study area}

This study was conducted from January 2009 to December 2009 in two popular veterinary clinics in Jos namely; Jos Veterinary Clinic located in Jos North and the ECWA Veterinary Clinic located in Jos South Local Government Areas of Plateau State Nigeria. The two sites were selected to give a fair and unbiased sample range of ticks on dogs in Jos. Plateau State is located in the North Central Nigeria and lies between latitude $7^{\circ} 11^{\prime} \mathrm{N}$ and $7^{\circ} 25^{\prime} \mathrm{E}$ of the equator and occupies about $53,585 \mathrm{KM}^{2}$ (Plateau State Diary 2016). 


\section{Sampling methods}

Three hundred (300), male and female dogs between the ages of one and eight were presented to the two clinics during the study period to examine the presence and infestation rate by ticks, and were randomly selected for the study. Dogs under two years were regarded as puppies, between two and five years as adolescent and above five years as adults. On each day of sample collection, ticks observed on the body of dogs were gently removed using forceps and transferred to labelled bottles containing $70 \%$ ethanol. Smaller ticks were warmed and cleared of debris in a test tube containing $3 \mathrm{mls}$ of Potassium Hydroxide, it was rinsed with distilled water and dehydrated through grades of ethanol, 26 -96\%. Ticks were cleared in Xylem and mounted in Canada Balsam (soulsby, 1982).

Identification of ticks

All ticks collected were carefully identified using taxonomic keys produced by (Nuttal and Warbuton, 1911a; Nuttal and Warbuton, 1911b: Hoogstraal, 1958; Crosskey, 1960; Chandler, and Read, 1961; Hoogstraal et al., 1968 and Soulsby, 1982) after examining the characteristic features visually with the help of a dissecting microscope.

\section{Statistical analysis}

The proportions obtained in this study were compared using Chi-square test. The confidence level for the analysis was set at $95 \%$, and level of significant difference at $\mathrm{p}<0.05$.

\section{RESULTS AND DISCUSSION}

A total of 1,146 ticks were recovered from the 300 dogs during the study. Three species of ticks all drawn from the family ixodidae were identified. Rhipicephalus sanguineus was the most abundant species encountered 465(40.58\%), followed by Boophilus decoloratus 384(33.50\%), Haemaphisalis leachii was the least species encountered 297(25.92\%) (Table $1)$. This findings agrees with the reports by Iwuala and Okpala (1978a,b), James-Rugu and Idu (2008) who all reported the dominance of these species of ticks on dogs particularly $R$ sanguineaus, in their studies. Since Hoogstraal, had earlier reported that ixodid ticks are entirely mammalian parasites, dogs are therefore not excluded from infestation by these species of ticks, hence the reason for their abundance.

Table 1: Relative abundance of tick species encountered on dogs during the study

\begin{tabular}{lcc}
\hline Tick species & Number encountered & \% occurrence \\
\hline Rhipicephalus sanguineus & 465 & 40.50 \\
Boophilus decoloratus & 384 & 33.50 \\
Haemaphisalis leachii & 297 & 25.92 \\
Total & 1,146 & \\
\hline
\end{tabular}

Of the 154 male dogs examined $70(45.16 \%)$ were infested with ticks, while $85(54.84 \%)$ out of the 146 female counterpart examined were infested with ticks. Female dogs were observed to be more infested with ticks than the male host (Table 2). This is not unconnected to the fact that female dogs usually form a sedentary habit during the care of their new born where they are easily infested by ticks. Similarly,
Tanwia (1989) reported that female dogs are highly susceptible to tick infestation than the male animal. Another possible reason could be the feeding habbit of the female dogs as observed during the study. They feed more than their male counterparts during pregnancy. As they search for food, they come in contact with the ticks thereby getting infested.

Table 2: Infestation of ixodid ticks in relation to sex of dogs

\begin{tabular}{|c|c|c|c|c|c|c|}
\hline $\begin{array}{l}\text { Sex of } \\
\text { Dogs }\end{array}$ & $\begin{array}{l}\text { No. } \\
\text { Examined }\end{array}$ & $\begin{array}{l}\text { No. with } \\
\text { Ticks(\%) }\end{array}$ & $\begin{array}{l}\text { Total No. } \\
\text { of } A(\text { Mean })\end{array}$ & $\begin{array}{c}\text { Total No. } \\
\text { of } B(\text { Mean }) \text { of }\end{array}$ & $\begin{array}{c}\text { Total No } \\
\text { f C(Mean) Tic }\end{array}$ & $\begin{array}{l}\text { Total No. of } \\
\text { ks(Mean) }\end{array}$ \\
\hline Male & 154 & $70(45.16)$ & $185(2.64)$ & $145((2.07)$ & $187(2.67)$ & $517(7.40)$ \\
\hline Female & 146 & $85(54.84)$ & $280(3.30)$ & $152(1.80)$ & $197(2.32)$ & $629(7.40)$ \\
\hline Total & 300 & 155(51.67) & $465(3.00)$ & $297(1.90)$ & ) $\quad 384(2.47$ & $\quad 1,146(7.40)$ \\
\hline
\end{tabular}

Infestation of tick species in relation to age of dogs showed that adolescent dogs were more susceptible to tick infestation (47.10\%) than the adult $(30.90 \%)$ and the young dogs $(22.00 \%)$.
The infestation was higher in adolescent dogs when compared to the adult and the young dogs in this study (Table 3 ). 
This finding corroborated the report by JamesRugu, (2001), Shitta, (2009) and Arong et al., (2011) who observed that adult and adolescent dogs were more infested by ticks than the young animals. This might be due to a lot of attention and care given to the young dogs than the adult and adolescent host who are left to move about indiscriminately where they come in contact with ticks.

Table 3: Infestation of ixodid ticks in relation to age of dogs

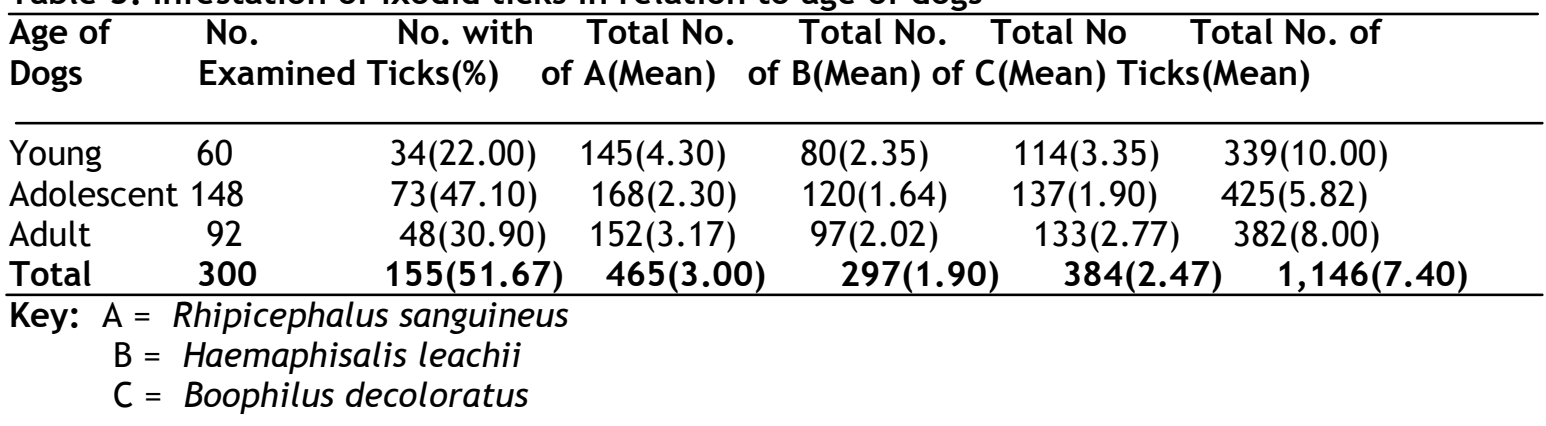

\section{Conclusion}

The overall result revealed that three species of ticks infests dogs in the study area. The study further indicates that the prevalence of ticks on dogs is high amongst the female dogs and adolescent ones when compared to other studies. This suggested that tick control

\section{References}

Arong, G.A., Shitta, K.B., James-Rugu, N.N. and Effanga, E.O. (2011). Seasonal variation in the abundance and distribution of ixodid ticks on mongrel, Alsatian and mixed breeds of dogs (Canis familiaris) in Plateau State, North-Central Nigeria. The Nigerian Journal of Parasitology, 32(1):7-10.

Chandler, A.C. and Read, C.P (1961) Introduction to parasitology. John Wiley and Sons Inc. New York and London. Pp 571-580.

Crosskey, D.A. (1960). Comparative external morphology and taxonomy of nymphs of the trombiculidae (Acarina). University of Kasas Science Bulletin 7:35-39

De-Castro, J.J. (1997). Sustainable ticks and tick-borne diseases control in livestock improvement in developing countries. Veterinary Parasitology, 71:77-97.

George, B.D.J. (2003). Comparative study of Haemocyte populations in Babesia sp. Infected and unaffected Boophilus decoloratus (Koch) ticks. Nigerian Journal of Entomology, 20:49-55.

Hoogstraal, H., Kohls, G.M. and Parish, D.W. (1968). Studies on South Asian Haemaphisalis ticks (ixodidea: ixodidae) $H$. kaiseriana susphilipensis sp. N., A parasite of Luzon and Mindanao Boars. Journal of Parasitology, 54:616-621. measures for dogs should be concentrated on the dominant tick species. Frequent dipping of these animals in acaricides, grooming and restriction of movement is highly recommended to help reduce tick burdens and subsequently tick-borne infections.

Hoogstraal, H. (1956). Ticks of the Sudan. US Naval Medical Research Unit (3) Cairo Egypt, 110pp.

Hoogstraal, H. (1958). Notes on African Haemaphisalis ticks iv. Description of Egyptian population of the yellow tick H. leachii leachii (Audoin 1827) (ixodidea: ixodidae), Journal of Parasitology, 44:548-558.

Hoogstraal, H. (1964). Notes on African Haemaphisalis ticks vi. H. Spinulosa Neumann and relation to biological and nomenclatorial problems in the H.leachii, group of Africa and Asia (ixodidea: ixodidae), Journal of Parasitology, 50(6):786-792.

Iwuala, M.O.E. and Okpala, I. (1978a). Studies on the Ectoparasitic fauna of Nigerian Livestock I: Types and distribution patterns. Bulletin of Animal Health and Production in Africa, XXVI (4):339-350.

Iwuala, M.O.E. and Okpala, I. (1978a). Studies on the Ectoparasitic fauna of Nigerian Livestock II: Seasonal infestation rate. Bulletin of Animal Health and Production in Africa, XXVI(4):351-359.

James-Rugu, N.N. (2001). A study of the haemoparasites of dogs, pigs and cattl in Plateau State. Nigerian Journal of Science and Technology, 7:20-27.

James-Rugu, N.N. (2002). Studies on ticks and tick-borne parasite of dogs in Jos, Plateau state. Zuma Journal of Pure and Applied Sciences, 4(2):29-35. 
James-Rugu, N.N. and Idu, M.E. (2008). Ectoparasites of some domestic animals in Makurdi metropolis, Benue State, Nigeria. Journal of Pest, Disease and Vector Management, 8:471-477.

Mohammed, A.N. and Agbede, R.I.S. (1980). Control of ectoparasites on ruminants in Nigeria. In proceedings of national seminar on "The current problem facing the leather industry in Nigeria. LERIN, Zaria, September, 24-26 1980.

Nuttal, G.H.F. and Warbuton, C. (1911a). Ticks: A monograph of the ixodidae part II. Ixodidae: Cambridge, Cambridge University Press, 1-348.

Nuttal, G.H.F. and Warbuton, C. (1911b). Ticks: A monograph of the ixodidae part III. Ixodidae: The genus Haemaphisalis. Cambridge, Cambridge University Press, 1-550.
Pegram, R.G. (1976). Ticks (Acarina, Ixodidae) of the Northern region of the Somali Democratic Republic. Bulletin of Entomology Resources, 66:345-363.

Plateau State Government of Nigeria, (2016) Diary pp8.

Shitta, K.B. (2009). Studies on Babesia canis infection and its vectors in dogs in parts of Plateau State, Nigeria. M.Sc. Thesis, Department of Zoology, University of Jos Nigeria.

Soulsby, J.I. (1982). Helminths, arthropods and protozoa of domesticated animals, $7^{\text {th }}$ Edition William and Wilkins Company, Baltimore. USA:121-155.

Tanwia, N.N.A. (1989). Aspect of the Biology and ecology of ticks of livestock in parts of Plateau State. Ph.D. Thesis, Department of Zoology, University of Jos, Nigeria.

Zeleke, M. and Bekele, T. (2004). Species of ticks on camels and their seasonal population dynamics in Eastern Ethiopia. Tropical Animal Health and Production, 36:225-231. 